\title{
SUSTENTABILIDADE: LOGÍSTICA REVERSA E RESPONSABILIDADE DOS DETRITOS DE CONSUMO
}

\author{
Pâmela Gabriela Blanco de Mattos (Universidade Veiga de Almeida) pamelagbm2@gmail.com \\ Raquel Neves Umbelino (Universidade Veiga de Almeida) raquel_umbelino@hotmail.com \\ Kathleen Mendonça Vieira (Universidade Veiga de Almeida) kathleenvieira2@gmail.com \\ Ana Clara Fernandes Bezerra (Universidade Veiga de Almeida) aclarafb@ hotmail.com \\ Daiane Rodrigues do Santos (Universidade Veiga de Almeida) daiane.santos@uva.br
}

\section{Resumo}

O presente artigo denota uma pesquisa sobre os conhecimentos teóricos da logística reversa e como a preocupação com a sustentabilidade ambiental das operações tem crescido atualmente. Apesar do Brasil ser um país em desenvolvimento, há multinacionais que já adotam o recurso da logística reversa, que entre os conceitos introduzidos está a responsabilidade compartilhada pelo ciclo de vida dos produtos, preocupando-se até a fase final do produto, seja ele resíduo ou rejeito. Entende-se como ciclo de vida de produto o "conjunto de atribuições individualizadas e encadeadas dos fabricantes, importadores, distribuidores e comerciantes, dos consumidores e dos titulares dos serviços públicos de limpeza urbana e de manejo dos resíduos sólidos, para minimizar o volume de resíduos sólidos e rejeitos gerados, bem como para reduzir os impactos causados à saúde humana e à qualidade ambiental decorrentes do ciclo de vida dos produtos, nos termos desta Lei." De acordo com a Lei $\mathrm{n}^{\circ} 12.305$, de 2 de agosto de 2010, e seu regulamento, Decreto $\mathrm{N}^{\mathrm{o}} 7.404$ de 23 de dezembro de 2010, citada anteriormente, as empresas são responsáveis desde a criação até o descarte daquele produto, tornando-as obrigadas a aceitarem o retorno de seus produtos descartáveis. Esta pesquisa tem como objetivo geral: analisar a logística reversa, destacar os principais conceitos, levantar informações sobre as suas principais contribuições ao meio ambiente e como as empresas têm se adaptado a implementação desse processo logístico.

\section{Palavras-chave: logística reversa, sustentabilidade, lei, produtos}

\section{Introdução}

As condições econômicas e ambientais nas quais as empresas contemporâneas operam estão em um processo de mudança altamente dinâmico e distintos das condições que predominavam 
em décadas anteriores, como na época das primeiras Revoluções Industriais. As informações são disseminadas de forma mais abrangente e veloz em função do avanço tecnológico o que acarreta consumidores mais informados e conscientes, em paralelo, o aumento do consumo de bens e serviços pelos agentes econômicos estão gerando a escassez de recursos naturais. Portanto, as empresas devem ser capazes de se adaptar às mudanças que estão ocorrendo e assim garantir não apenas seu desenvolvimento, mas também a sua existência.

A principal motivação do estudo é a limitação dos recursos em nosso planeta associada às vontades ilimitadas dos agentes econômicos. No âmbito empresarial, as estratégias para o desenvolvimento sustentável estão relacionadas à limitação do impacto ambiental adverso exercido pelos produtos e serviços fornecidos, reduzindo o consumo de materiais e energia, mitigando assim a quantidade de resíduos e emissões.

A logística reversa está diretamente ligada ao esforço para melhorar as operações e a aquisição de recursos econômicos e benefícios ecológicos, a partir de procedimentos e meios para recolher e dar andamento ao pós-venda e/ou pós-consumo empresarial. Além disso, tal prática está prevista na Política Nacional de Resíduos Sólidos, podendo diminuir os custos da empresa e usá-la como vantagem competitiva. Segundo o Ministério do Meio Ambiente a PNRS, prevê a prevenção e a redução na geração de resíduos, tendo como proposta a prática de hábitos de consumo sustentável e um conjunto de instrumentos para propiciar o aumento da reciclagem e da reutilização dos resíduos sólidos e a destinação ambientalmente adequada dos rejeitos.

A logística reversa surgiu como um meio de recuperar produtos visando uma maior sustentabilidade e economia de custos com o reaproveitamento do material coletado. A principal diferença da logística reversa para a logística tradicional está na sustentabilidade. Este artigo demonstra a importância da logística reversa em ganhos financeiros, logísticos, sociais e ambientais através da análise do ciclo logístico atual no ramo de embalagens de produtos amplamente presentes na sociedade. Apresentando o questionamento de quem é o responsável pelo retorno das embalagens, o estudo aponta soluções já apresentadas através do marketing verde, gerando uma preocupação maior dos consumidores instigando cada vez mais a responsabilização ambiental por parte das empresas, trazendo visibilidade no ramo empresarial. É necessária a comprovação dos benefícios utilizando os dados apresentados e demonstrando o detalhamento da cadeia logística apontando a linha tênue entre logística direta e reversa. Há muitos exemplos de logística reversa que podem ser observados hoje em 
dia, empresas como Quem Disse Berenice? e Coca-Cola são apenas o começo de como a logística reversa pode estar presente em todos os ramos.

O presente artigo está dividido em seis seções, a subsequente (seção 2) aborda a questão da logística reversa, o histórico da logística reversa no Brasil apresenta um breve resumo dos programas de logística reversa e sua evolução ao longo dos anos. A seção 3, informa a importância do marketing verde, para a construção de uma imagem positiva da empresa em parceria com a redução dos impactos ambientais. Já a seção 4, aborda o mercado sustentável e a economia circular no Brasil. Na seção seguinte, são apresentadas as conclusões do estudo.

\section{Logística reversa}

Logística reversa, em um sentido amplo, significa todas as operações envolvendo a reutilização de produtos e materiais. Para Daher et al. (2006) logística reversa refere-se a todas as atividades de logística para coletar, desmontar e processar produtos, peças e materiais relacionados ao produto ou bem, garantindo uma recuperação sustentável. A logística reversa pode ser definida como uma área da logística empresarial que planeja, opera e controla o fluxo e as informações do retorno dos bens após a venda e consumo por meio dos canais de distribuição reversos, agregando-lhes valores de diversas naturezas: econômico, ecológico, legal, logístico, de imagem corporativa, dentre outros (LEITE, 2003).

A logística reversa implica a devolução de produtos com pouca ou nenhuma utilidade para os agentes econômicos, como por exemplo produtos obsoletos, resíduos e embalagens para reutilização, reciclagem e/ou descarte. Para Rubio et al. (2019) a logística reversa está focada na recuperação de produtos, uma vez que eles não são mais desejados pelos consumidores ou não podem mais ser usados, a fim de obter um retorno econômico através da reutilização, reciclagem ou remanufatura minimizando o dano ambiental e/ou econômico proveniente de seu descarte total.

De acordo com Kulikova (2016), a logística reversa é um tema adicional na história da logística e da gestão da cadeia de suprimentos. Para a autora essa atividade é uma parte crucial da sustentabilidade logística, como demonstrado na figura 1. 
Figura 1 - Logística reversa como parte da logística verde

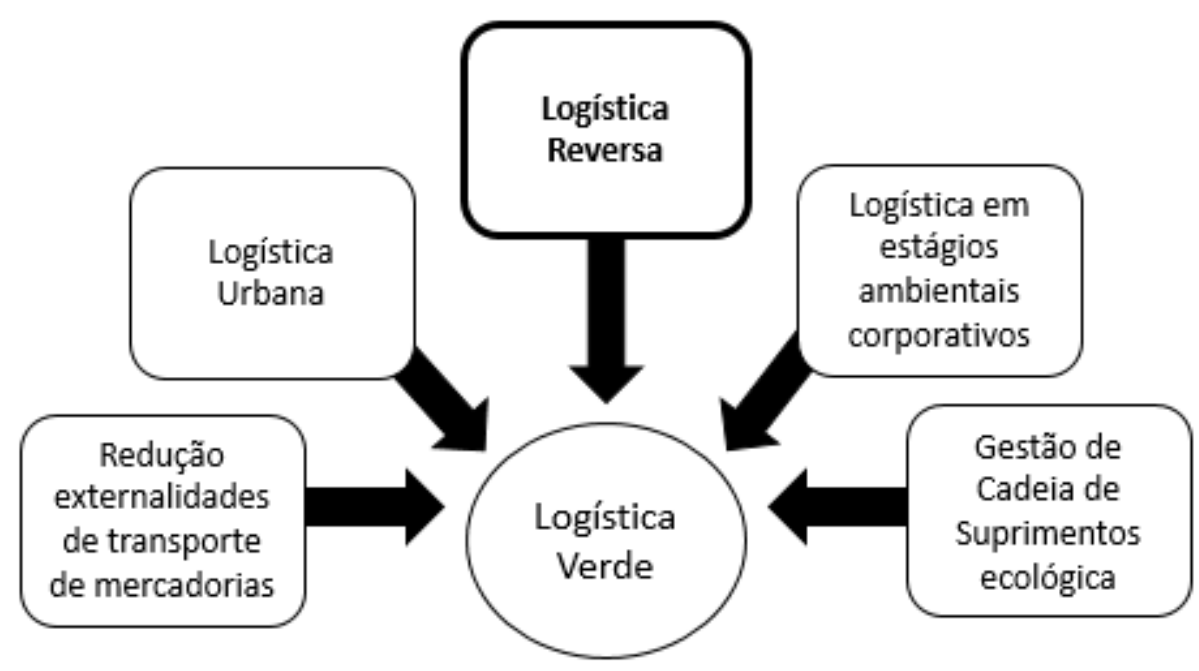

Fonte: Elaborado pelos autores com base em Kulikova (2016) (imagem traduzida inglêsportuguês)

A logística verde é a parte da logística que se preocupa com os aspectos e impactos ambientais causados pela atividade logística. Para Santos et al. (2015) a logística verde tem como principal objetivo coordenar as atividades dentro de uma cadeia de suprimentos de tal forma que as necessidades dos benefícios sejam atendidas com o "menor custo" para o meio ambiente. Aqui, neste caso, menor custo ambiental está ligado a alterações climáticas, poluição do ar, deposição de resíduos (incluindo os resíduos de embalagens), degradação do solo, ruído, vibração e acidentes. (QUIUMENTO, 2011 apud Santos et al. (2015)).

Na figura 2, é apresentado os 3 tipos de logística reversa. 
Figura 2 - Os três tipos de logística reversa

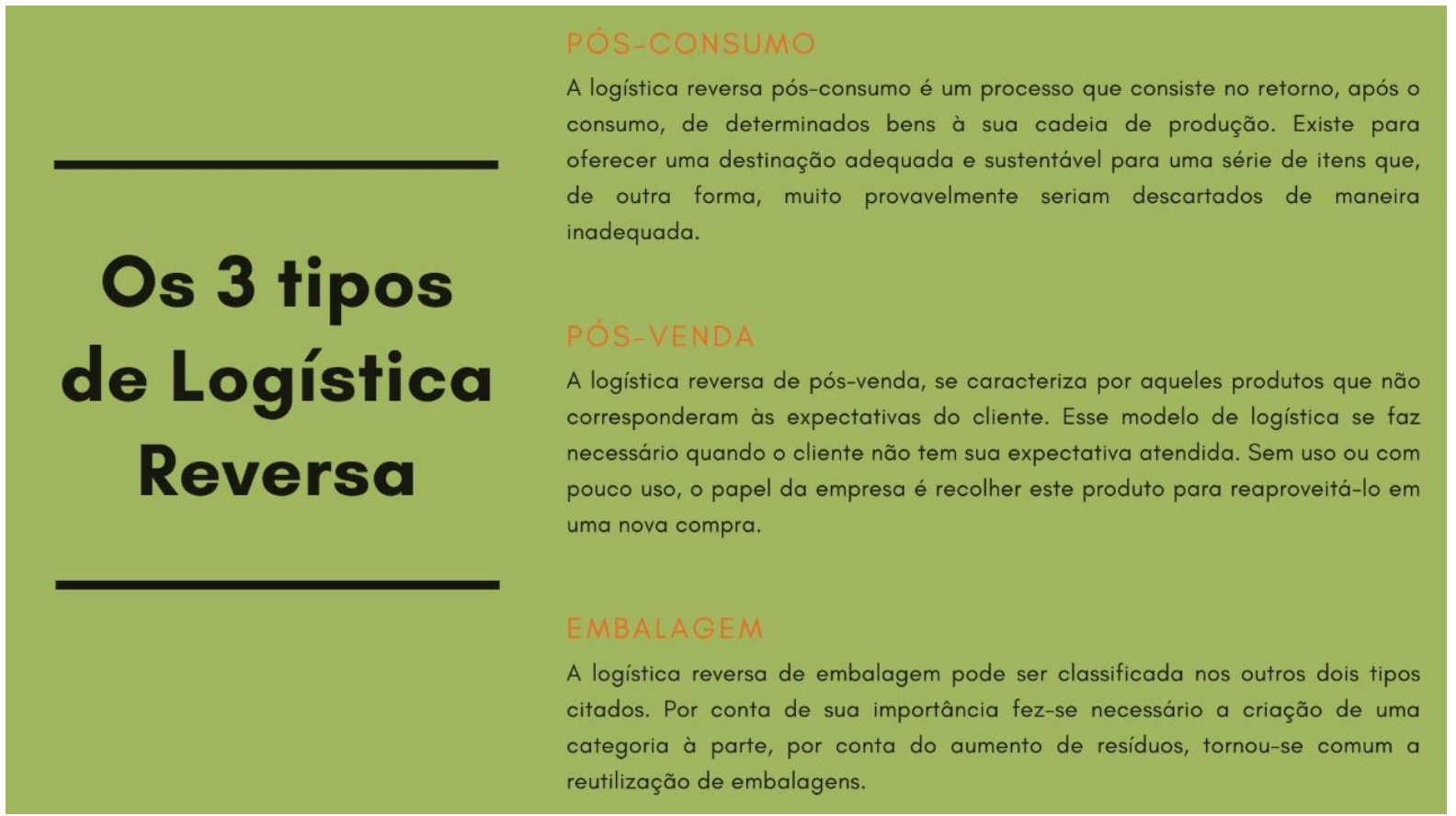

Fonte: Elaborado pelos autores com base em LIVA (2003)

\subsection{O histórico da logística reversa no Brasil}

Em 2010 foi sancionada pelo Governo Federal, a Política Nacional de Resíduos Sólidos (PNRS). Trata-se da Lei ${ }^{\circ}$ 12.305/10, regulamentada pelo Decreto 7.404/10, na qual, objetiva a organização nacional do descarte do lixo. Quando lançada, a lei visava uma responsabilidade compartilhada, entre fabricantes, importadores, distribuidores, comerciantes, consumidores e o poder público, pelos resíduos resultantes do pós-consumo dos produtos. Com objetivos como a proteção da saúde pública, preservação do meio ambiente e a sustentabilidade dos meios de produção e consumo de bens e/ou serviços, a PNRS também consta exigências às empresas quanto à estruturação de Sistemas de Logística Reversa no país.

A responsabilidade pelo ciclo de vida dos produtos é considerada como responsabilidade compartilhada entre fabricantes, importadores, distribuidores e comerciantes, consumidores e Estado. Isto significa, para Filho et. al. (2015), dividir as responsabilidades entre sociedade, iniciativa privada e poder público. Tadeu et al. (2012) afirmam em seu artigo que é necessário compartilhar as responsabilidades entre poder público, empresas e sociedade e formular dispositivos de controle como o efetivo cumprimento de normas estabelecidas. 
Com a PNRS, a responsabilidade compartilhada acerca do ciclo de vida dos produtos foi acolhida com instrumentos para a implementação dela, dessa forma, a logística reversa surge como forma de viabilizar o reaproveitamento dos resíduos sólidos dos processos produtivos do país, e assim diminuir a quantidade de resíduos descartados incorretamente (Ministério do Meio Ambiente). Diversos setores no país, após a implementação da lei, estão em buscas de formas de elaborar e estruturar os sistemas de logística reversa de produtos e embalagens pósconsumo, com o objetivo de reciclá-los reduzindo o impacto ao meio ambiente e reinserindoos no processo produtivo como matéria-prima.

De acordo com o Plano Nacional de Resíduos Sólidos (2011), apesar de ser um marco para a questão ambiental brasileira, a PNRS não foi a primeira Lei implantada no país a respeito do tema de gestão pós-consumo. A Lei Federal n ${ }^{\circ}$ 9.974/2000 e o Decreto Federal nº 4.074/2002, alteram a Lei $\mathrm{n}^{\mathrm{o}}$ 7.802, de 11 de julho de 1989, que dispõe sobre a pesquisa, a experimentação, a produção, a embalagem e rotulagem, o transporte, o armazenamento, a comercialização, a propaganda comercial, a utilização, a importação, a exportação, o destino final dos resíduos e embalagens, o registro, a classificação, o controle, a inspeção e a fiscalização de agrotóxicos, seus componentes e afins, e dá outras providências. Foi acrescentado, no art. 19 da Lei nº 7.802, de 1989, o parágrafo único que diz:

"As empresas produtoras e comercializadoras de agrotóxicos, seus componentes e afins, implementaram, em colaboração com o Poder Público, programas educativos e mecanismos de controle e estímulo à devolução das embalagens vazias por parte dos usuários, no prazo de cento e oitenta dias contado da publicação desta Lei." (art. 19 da Lei $\mathrm{n}^{\mathrm{o}}$ 7.802, de 1989)

\subsection{Programas de logística reversa}

A discussão e debates sobre o tema logística reversa vem tomando espaço no país, em 1999 surgiram os programas de logística reversa como o programa Sistema Campo Limpo, cuja finalidade é realizar a logística reversa de embalagens vazias de defensivos agrícolas em todas as regiões do Brasil. A iniciativa está a cargo do Instituto Nacional de Processamento de Embalagens Vazias (inpEV), fundado em 2001, que tem como objetivo fazer a gestão pós- 
consumo desse tipo de embalagem. Na figura 3 é visto que, em 2018, o sistema processou 44.261 toneladas de embalagens vazias de defensivos agrícolas, o que representa $94 \%$ do total de produtos desse tipo comercializados no país. Trata-se da terceira queda seguida e da menor quantidade em quatro anos, uma tendência já esperada, pois reflete mudanças sofridas no perfil das embalagens fabricadas: elas têm ficado mais leves por empregarem número cada vez menor de materiais.

Figura 3 - Evolução da destinação adequada de embalagens de defensivos agrícolas (t/ano)

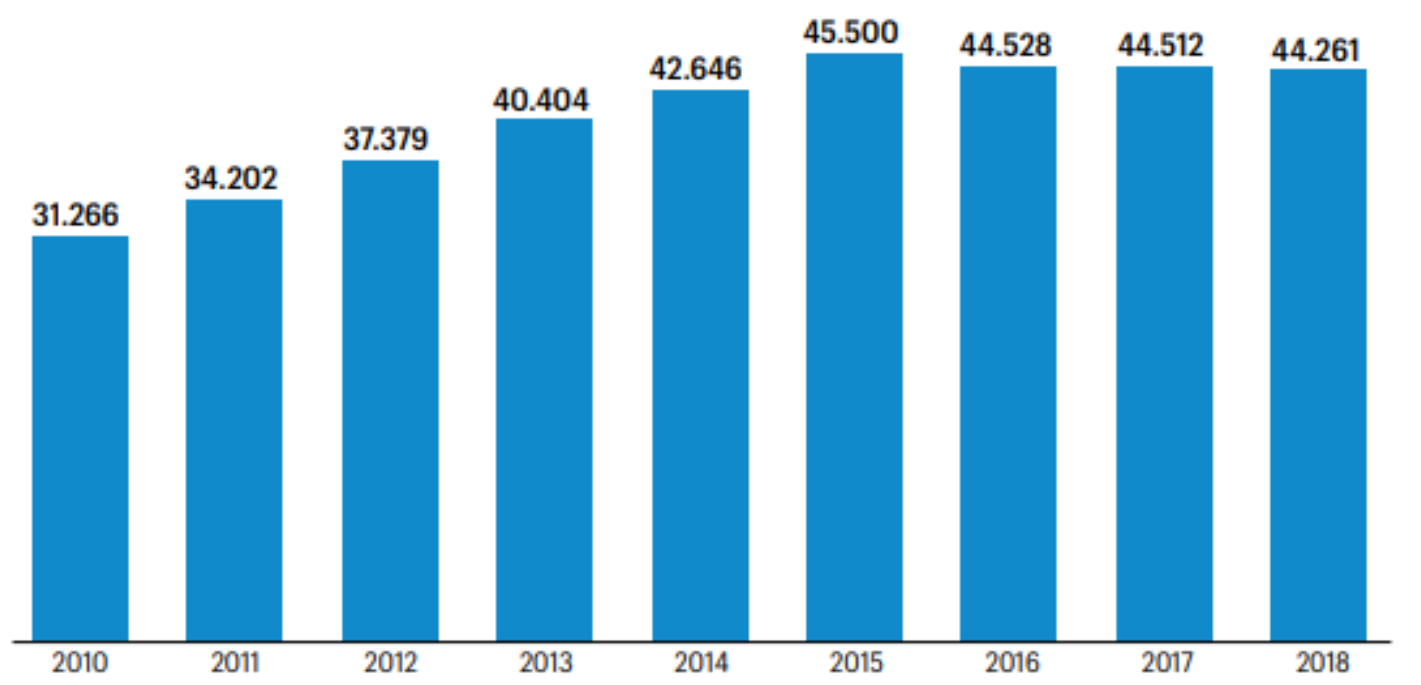

Fonte: Instituto Nacional de Processamento de Embalagens Vazias (inpEV)

Outro programa que deve ser comentado é a Reciclanip, a entidade gerenciadora da logística reversa de pneus que não podem mais ser reaproveitados (pneumáticos inservíveis), representante dos fabricantes nacionais desses produtos. Sua atuação estende-se por todo o país, impulsionada pela Resolução Conama n 416/2019, que estabeleceu a obrigatoriedade da presença de pontos de coleta nos municípios com população acima de 100 mil habitantes (Gardin et al. (2010)). Do início do programa, em 1999, até o final de 2017, cerca de 4,5 milhões de toneladas de pneus inservíveis foram coletadas e corretamente destinadas - o equivalente a 916 milhões de pneus de carro de passeio. Houve aumento de 0,22\% na quantidade de pneus recuperados, como demonstrado na figura 4. 
Figura 4 - Evolução da quantidade de pneus inservíveis coletados e corretamente destinados no Brasil (em mil toneladas)

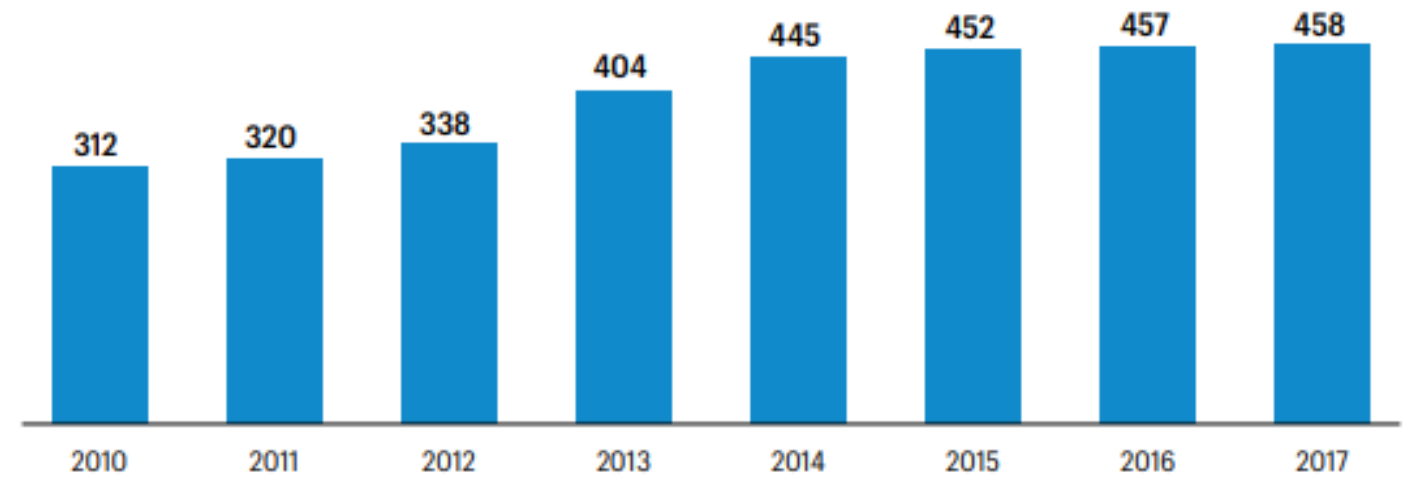

Fonte: Reciclanip (2017)

Já a respeito do volume de materiais recicláveis, o programa Dê a Mão para o Futuro Reciclagem, Trabalho e Renda - tem como principal função ser uma solução viável na gestão de resíduos sólidos pós-consumo das empresas associadas à Abihpec, à Abipla e à Abimapi. O foco é inclusão social a partir de geração de emprego e renda para os catadores de materiais recicláveis. Desde 2013, o programa acompanha o volume de materiais recicláveis coletados pelas cooperativas - elas eram 24 no início, agora já somam 144. Como apresentado abaixo, na figura 5, em todo o período, foram recuperadas 391.526 toneladas de resíduos. Houve recuperação de $22 \%$ das embalagens pós-consumo colocadas no mercado pelas empresas participantes do programa, movimentando cerca de $\mathrm{R} \$ 62$ milhões.

Figura 5 - Volume de materiais recicláveis recuperados por meio do programa Dê a Mão para o Futuro (t/ano)

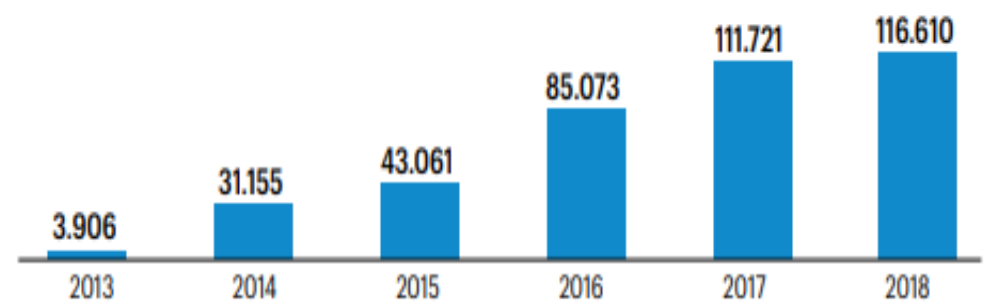

Fonte: Abihpec (2019)

$\mathrm{Na}$ figura 6, apresentamos uma timeline com alguns exemplos de programas de logística reversa no Brasil. 
Figura 6 - Programa de logística reversa no Brasil.

\section{PROGRAMAS DE LOGISTICA REVERSA NO BRASIL}

\section{RECICLANIP}

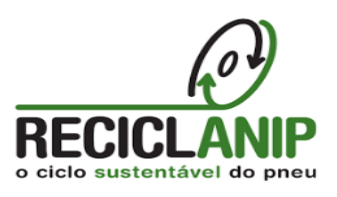

1999

A Reciclanip é considerada uma das maiores iniciativas da indústria brasileira na área de responsabilidade pós-consumo, também conhecida como logística reversa. O trabalho de coleta e destinação de pneus inserviveis realizado pela entidade é comparável aos maiores programas de reciclagem desenvolvidos no país.

Sistema Campo Limpo

2002

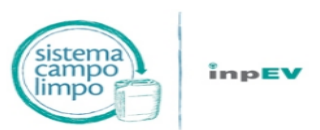

Desde o início da operação, em 2002, o Sistema Campo Limpo vem sendo ampliado e atualmente assegura a destinação ambientalmente correta de cerca de $94 \%$ das embalagens plásticas primárias e $80 \%$ do total de embalagens vazias de defensivos agrícolas comercializadas.

Instituto Jogue Limpo 2005

O Instituto Jogue Limpo é uma associação de empresas fabricantes ou importadoras de óleo lubrificante. É a entidade gestora responsável por realizar a logística reversa das embalagens plásticas de óleo lubrificante usadas e de óleo lubrificante usado ou contaminado (OLUC).

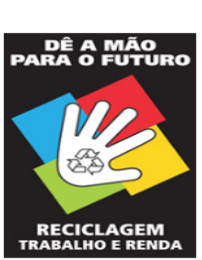

Dê a Mão Para o Futuro

2006

O Programa "Dê a Mão para ○ Futuro" fol desenvolvido como uma alternativa viável para suas associadas no gerenciamento de resíduos sólidos pós-consumo. Tem como principal função ser uma solução viável na gestão de resíduos sólidos pós-consumo das empresas associadas à Abihpec, à Abipla e à Abimapi.

\section{RECICLUS}

2015

A Reciclus é uma organização sem fins lucrativos, idealizada, formada e sustentada por Empresas Fabricantes, importadores de lâmpadas equipamentos de iluminação e seus stakeholders. A Reciclus organiza e desenvolve a coleta e o encaminhamento correto de lâmpadas fluorescentes, através de pontos de coleta distribuídos pelo Brasil. 


\section{Marketing verde}

A sociedade a cada dia aumenta as pressões para que as empresas desenvolvam produtos e processos ecologicamente corretos, e com isso a reciclagem ganha força e a logística reversa é um dos principais motores deste movimento (COELHO, 2009). Além de contribuir legitimamente para a redução dos impactos ao meio ambiente, a empresa que faz ganha o prestígio de uma imagem positiva.

O termo marketing verde ou ecológico, surgiu nos anos 70, quando a American Marketing Association - AMA, realizou um Workshop com a intenção de discutir o impacto do marketing sobre o meio ambiente. Após esse evento surgiu a definição do marketing como: "O estudo dos aspectos positivos e negativos das atividades de marketing em relação à poluição ao esgotamento de energia e ao esgotamento dos recursos não renováveis".

Segundo Guimarães, Viana \& Costa (2015), uma empresa considerada 'verde' é aquela que aplica em toda a sua conjuntura investimentos e ações ambientais, desde a fabricação e a produção de bens até as suas relações com clientes, fornecedores e funcionários. Necessitando traçar uma estratégia de marketing ambiental que esteja de acordo com o que se chama os pilares da sustentabilidade: reciclar, reutilizar e reduzir, atingindo todos os setores da empresa, tanto internamente, promovendo a conscientização dos trabalhadores e estabelecendo a sustentabilidade como um dos valores da empresa, quanto externamente, influenciando fornecedores e clientes e a sociedade em geral para obtenção de práticas ecologicamente viáveis.

Lopes \& Pacagnan (2014) identificaram que um dos principais motivos que levam as empresas a adotar práticas de gerenciamento na área ambiental é a melhoria na imagem e na reputação. A prática do marketing verde é determinante para que esse objetivo seja respondido. A melhoria de imagem de uma empresa está ligada aos diferenciais e valores agregados aos seus produtos.

\section{Mercado sustentável}

Com o constante crescimento populacional no Brasil, há cada vez mais produtos sendo consumidos e consequentemente um aumento de resíduos no país. Tal cenário se mostra 
extremamente prejudicial à sobrevivência, pois traz consigo diversos problemas ambientais como os citados no tópico Logística Reversa (QUIUMENTO, 2011 apud Santos et al. (2015)).

A demanda por produtos sustentáveis vem crescendo cada vez mais no Brasil, o que vem sendo concretamente refletido nas estratégias e nas vendas da indústria e do varejo no país. Com toda a facilidade de acesso à informação que se tem hoje em dia, a população vem se tornando cada vez mais consciente e preocupada em relação ao futuro, o que justifica a ascensão da busca por produtos que de certa forma proporcionam ao consumidor uma sensação de contribuição com o meio ambiente.

De acordo com o estudo Estilos de Vida 2019 da Nielsen, o meio ambiente já aparece como uma das 10 principais preocupações do brasileiro, ficando atrás apenas da violência, serviços públicos, aumento no custo de vida, educação e economia. Logo, as empresas que oferecem produtos sustentáveis possuem uma grande vantagem competitiva.

A fim de solucionar ou ao menos amenizar os impactos ambientais, de acordo com o relatório Logística Reversa de Equipamentos Eletroeletrônicos Análise de Viabilidade Técnica e Econômica (2013), as empresas vêm buscando alternativas tanto em sua produção quanto na logística reversa de seus produtos, de forma que possam ser reutilizados ou reaproveitados. Esse sistema é caracterizado na chamada economia circular, na qual os produtos não viram lixo ao fim de sua vida útil, mas sim matéria-prima capaz de gerar novos produtos.

De acordo com informações divulgadas no site da empresa Unilever, companhia de produtos de higiene e beleza, de uma perspectiva puramente comercial, descartar plástico não faz sentido. Os resíduos de embalagens plásticas representam uma perda de US \$ 80 a US \$ 120 bilhões para a economia global a cada ano, de acordo com o Fórum Econômico Mundial. É necessária uma abordagem mais circular, onde não apenas usamos menos embalagens, mas também projetamos as embalagens que usamos para que possam ser reutilizadas, recicladas ou compostadas. Um uso mais circular dos materiais significa custos mais baixos e menos desperdício. Isso significa novas fontes de valor para nossos clientes e consumidores, melhor gerenciamento de riscos de matérias-primas e abordagens aprimoradas da cadeia de suprimentos. 


\subsection{Economia circular no Brasil}

Atualmente no Brasil existem muitas organizações alinhadas com a economia circular (Figura 7). É importante salientar que não somente uma embalagem pode ser reaproveitada, mas também alguma matéria-prima utilizada na produção de um produto, como é o caso do McDonald's.

Figura 7 - Economia circular

\section{Economia Circular}
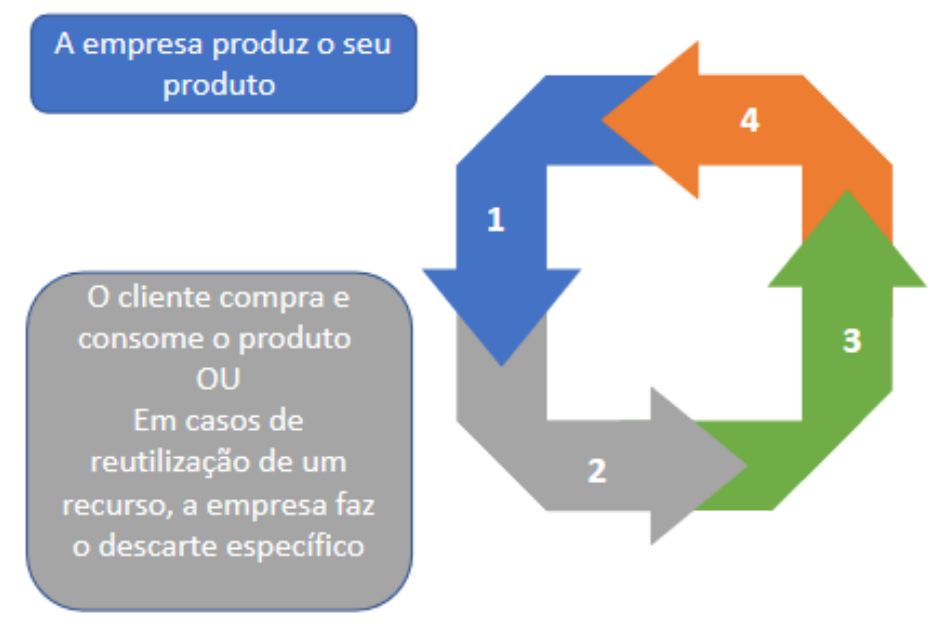

Essa embalagem é reaproveitada na produção de um novo produto como matéria-prima

OU

O recurso produtivo é reaproveitado para um novo processo

A empresa recolhe a embalagem do produto ou o cliente retorna com ela OU

Em casos de reutilização de um

recurso, a empresa o encaminha para o local onde será reintroduzido

Fonte: Elaboração própria (2020)

A “Quem Disse, Berenice?”, pertencente ao Grupo Boticário e especializada em maquiagem, tem uma ação onde seus clientes pertencentes ao seu programa de fidelidade levam cinco embalagens vazias de qualquer produto da marca e trocam por um batom cremoso em uma de suas lojas físicas. As embalagens recolhidas são encaminhadas para o descarte correto por meio de cooperativas parceiras, que fazem todo o processo da reciclagem.

Outra companhia que atua no Brasil com uma proposta sustentável, essa por sua vez se tratando de uma multinacional, é a Coca Cola. Com uma mecânica simples, ela lançou a promoção "Junte e Troque", onde juntando cinco tampinhas amarelas com impressão vermelha e uma embalagem retornável vazia, o consumidor pode trocar grátis por uma garrafa retornável cheia do mesmo tamanho. Cada garrafa retornável é reutilizada até 20 vezes, 
garantindo menos embalagens produzidas e descartadas por ano. O gerente sênior de Operações da Coca Cola, Diogo Gioia, diz

\footnotetext{
"Nosso foco é fortalecer uma proposta que promove os momentos com a família e os amigos aliando, ainda, economia e cuidado com o meioambiente. Quem participa da ação tem a oportunidade de comprar Coca-Cola, Fanta ou Guaraná Jesus de forma mais acessível e sustentável".
}

A empresa McDonald's também possui um sistema de reutilização de seu material: o óleo usado para fritar as batatas fritas. Os caminhões recolhem em todas as filiais do Brasil o óleo que restou e o leva para uma análise. Em seguida, esse óleo é encaminhado para uma usina que o transforma em biocombustível, que é utilizado para abastecer os próprios caminhões da empresa.

\section{Conclusão}

A discussão e debates sobre o tema logística reversa vem tomando espaço no país. A responsabilidade pelo ciclo de vida dos produtos é considerada como responsabilidade compartilhada entre fabricantes, importadores, distribuidores e comerciantes, consumidores e Estado. Empresas importantes como McDonald's e Coca-Cola já estão materializando sua preocupação com o meio ambiente e consumo sustentável.

Tal estudo demonstrou a importância da logística reversa que está cada dia mais presente nas empresas no Brasil, muitas delas por conta da cultura de multinacionais, entretanto tal responsabilidade não é somente da empresa que produz o bem, mas também dos fornecedores e principalmente dos consumidores.

A logística reversa viabiliza ganhos financeiros, sociais e ambientais, pois minimiza diretamente os danos ao meio ambiente, visto que o produto com menor ou nenhuma utilidade para o agente não será descartado no meio ambiente e sim recolhido pela empresa e direcionado devidamente para outro fim ou outro consumidor que atribua utilidade ao mesmo. 


\section{Referências}

ABDI- Agência Brasileira de Desenvolvimento Industrial. Logística Reversa de Equipamentos

Eletroeletrônicos Análise de Viabilidade Técnica e Econômica. Brasília, 2013. Disponível em:

<http://www.mdic.gov.br/arquivos/dwnl_1416934886.pdf> Acesso em: 10 jan 2020.

ABRELPE. Panorama dos Resíduos Sólidos no Brasil. São Paulo, 2018-2019. Disponível em:

<http://abrelpe.org.br/panorama/> Acesso em: 10 jan 2020.

ADLMAIER, Diogo; SELLITTO, Miguel Afonso. Embalagens retornáveis para transporte de bens manufaturados: um estudo de caso em logística reversa. Production 17, no. 2, São Paulo, 2007.

ABRAS BRASIL. Dados da Nielsen mostra que brasileiros buscam por produtos mais saudáveis. 05 de Jul. de 2019. Disponível em:

<https://www.google.com/url?q=http://www.abras.com.br/clipping.php?area\%3D1\%26clipping\%3D68181\&sa= D\&ust=1580137618060000\&usg=AFQjCNFfKo0F3VTgreaK_6As9Ybv0t7eww> Acesso em: 02 fev 2020.

ALVARENGA, Antonio Carlos; NOVAES, Antonio Galvão N.. Logística aplicada: suprimento e distribuição física, 3.ed.São Paulo: 2000.

BARROSO, Joicy. Logística reversa: de responsabilidade social à estratégia empresarial. Pet Administração Ufc. 22 de Ago. 2017.

CHIROLI, Daiane Maria de Genaro. Logística verde: conceituação e direcionamentos para aplicação. Electronic Journal of Management, Education and Environmental Technology. Paraná, ago. de 2015.

COCA- COLA BRASIl; Retornável é um novo jeito de pensar economia e sustentabilidade; 2019.

Disponível em: <https://retornaveis.cocacola.com.br/> Acesso em: 10 jan 2020.

COCA-COLA BRASIL; Release; Coca-Cola Brasil promove nova campanha para estimular uso de embalagens retornáveis; 14 de ago. 2018. Disponível em:

<https://www.cocacolabrasil.com.br/imprensa/release/junte-troque-coca-cola-brasil-promove-nova-campanhapara-estimular-uso-de-embalagens-retornaveis> Acesso em: 31 jan 2020.

CRUZ, Cleide Ane Barbosa; SANTANA, Rodrigo Silva de; SANDES, Itallo Santiago Fonseca. A logística reversa como diferencial competitivo nas organizações. Revista Científica do ITPAC, Araguaína, v.6, n.4, Pub.9, Outubro 2013.

DAHER, Cecilio Elias; SILVA, Edwin Pinto la Sota; FONSECA, Adelaida Pallavicini. Reverse Logistics: Opportunity to Reduce Costs by Integrated Value Chain Management, BBR, Braz. Bus. Rev. Vitória, v. 3, n. 1, jan.-jun. 2006. 
FECOMÉRCIO SP; Resíduos sólidos logística reversa: O que o empresário do comércio e serviços precisa saber e fazer. São Paulo, 20 de Dez. de 2012. Disponível em:

<https://www.abras.com.br/pdf/cartilhalogisticareversa.pdf> Acesso em 30 jan 2020.

FORMIGONI, Alexandre; SANTOS, Susan da Costa; MEDEIROS, Beatriz Torres. Logística reversa e sustentabilidade para a melhoria da cadeia: Uma abordagem no panorama da reciclagem pet no Brasil. RMS, v.4, n. 3, 2014.

GARDIN, Josy Alvarenga Carvalho; FIGUEIRÓ, Paola Schmitt; NASCIMENTO, Luis Felipe. Logística Reversa de pneus inservíveis: Discussões sobre três alternativas de reciclagem para este passivo ambiental. Revista Gestão e Planejamento, Salvador, v. 11, n. 2, p. 232-249, jul./dez. 2010.

KULIKOVA. Olga. REVERSE LOGISTICS; Bachelor`s Thesis Business Logistics, University of Applied Sciences. Switzeland, abr. de 2016

LEITE, Paulo Roberto. Logística Reversa - Meio Ambiente e Competitividade; Pearson, 2ª Ed. 2010.

LIVA, Patricia Beaumord Gomes; PONTELO, Viviane Santos Lacerda; OLIVEIRA, Wedson Souza. Logística Reversa. In: Gestão e Tecnologia Industrial. IETEC, 2003.

LOPES, Valéria Neder; PACAGNAN, Mario Nei. Marketing verde e práticas socioambientais nas indústrias do Paraná. Revista Administração (São Paulo) v. 49, n. 1 São Paulo Jan.-Mar. 2014.

MENOS UM LIXO; Embalagens da indústria da beleza, você sabe quais se comprometem com o pós consumo?. Pub. 03 de maio de 2018. Disponível em: <https://www.menos1lixo.com.br/posts/embalagens-daindustria-da-beleza> Acesso em: 30 jan 2020.

MINISTÉRIO DO MEIO AMBIENTE; Logística Reversa. Disponível em:< https://www.mma.gov.br/cidadessustentaveis/residuos-perigosos/logistica-reversa.html> Acesso em: 29 jan 2020

MINISTÉRIO DO MEIO AMBIENTE; Plano Nacional de resíduos sólidos; Brasília, set. de 2011.

Planalto- Casa civil; LEI No 9.974, DE 6 DE JUNHO DE 2000. Disponível em:

<http://www.planalto.gov.br/ccivil_03/LEIS/L9974.htm> Acesso em: 31 jan 2020.

RUBIO, Sergio; PARRA, Beatriz Jiménez; MERA, Antonio Chamorro; MIRANDA, Francisco J.. Reverse Logistics and Urban Logistics: Making a Link; MDPI Sustainability; Switzeland, 2019.

SECRETARIA DO MEIO AMBIENTE DE SÃO PAULO; Logística Reversa; Caderno de Educação Ambiental; São Paulo, 2014.

QUEM DISSE BERENICE; Recicla. Disponível em: <https://www.quemdisseberenice.com.br/recicla> Acesso em: 02 fev 2020. 
FILHO, Sergio Thode; MACHADO, Carlos José Saldanha; VILANI, Rodrigo Machado; PAIVA, Julieta Laudelina; MARQUES, Mônica Regina da Costa. A logística reversa e a política reversa e a política nacional de resíduos sólidos: Desafios para a realidade brasileira. REGET, v. 19, n. 3, SEPT.-DEC., 2015.

UNILEVER; Waste and Packaging. Disponível em: <https://www.unilever.com/sustainable-living/reducingenvironmental-impact/waste-and-packaging/> Acesso em: 02 fev 2020. 